\title{
Measures of social class based on education for use in health studies in developing countries
}

\author{
H ZURAYK, S HALABI, AND M DEEB \\ From the Department of Epidemiology and Biostatistics, Faculty of Health Sciences, American University of \\ Beirut, Lebanon
}

SUMMARY In this paper we consider the appropriateness of education, compared to occupation and income, as a measure of social class for use in health-related studies in developing societies in transition. Three evaluation criteria were used, namely, the feasibility of constructing the measure, its sensitivity in reflecting relevant social class life conditions, and its ability to produce a family-level measure of social class. We used two data sets from community health surveys in areas of Amman city, Jordan, and in Beirut city, Lebanon, to define a family-based average educational score. We then proceeded, using the Beirut data, to test the score's ability to discriminate social class effects on family health, compared to a more standard representation based on the educational level of the head of the family. It was found that the performance of the average educational score was often better than, but not consistently superior to, the educational level of the head of the family.

Strong evidence has accumulated to date that social class is associated with mortality, morbidity, and disability rates. ${ }^{1}$ Thus, social class has been included as a variable in health and epidemiological studies either to control for possible confounding effects when testing aetiological hypotheses, or to derive possible clues to aetiology, or to point to differential health needs among population groups. ${ }^{2}$ Measurement of social class has varied across studies, and some investigations have been undertaken to evaluate the usefulness of different indicators of social class in detecting associations with health variables. We discuss the appropriateness of education, compared to occupation and income, as a measure of social class for use in health-related studies in developing societies in transition. We also test the ability of a family-based educational score to discriminate social class effects on family health compared to a more standard representation based on the educational level of the head of the family.

Data bases from two recent community surveys were utilised, one in areas within the city of Amman, capital of Jordan, and one in the city of Beirut, capital of Lebanon. The Amman sample ${ }^{3}$ covered 1667 families residing in 1981 in five squatter areas in Amman targeted for upgrading schemes by the Urban Development Department of Jordan. The survey gathered housing, demographic, and socioeconomic information, as well as health data, for a subsample of children under 3 years of age. The Beirut sample ${ }^{4}$ covered a random sample of 2752 families representing the residents of the city of Beirut in late 1983 and early 1984, excluding those temporarily displaced into the city because of the war. The survey gathered information on environmental conditions, on demographic and socioeconomic characteristics, and on morbidity and utilisation of health services for all individuals in the sample.

\section{Education as a measure of social class}

Conceptualisations and strategies used in developing measures of social class generally rely on social and economic properties, used either individually or in combination, and on scales representing individual awareness of a class system..$^{5-8}$ The properties most often used as determinants of social class are occupation, education, and income. Housing and area-based measures have also been used, as well as self and informer ranking scales. ${ }^{689}$ In developed country studies, occupation has been the most important indicator employed. ${ }^{67}$ It is either used alone, for example, the frequently used UK Registrar General's Social Classification, or in combination with other characteristics. Occupational prestige rankings have also been developed. They are constructed based on subjective occupational ratings of representative samples of respondents. ${ }^{7}$ Duncan's Socioeconomic Index is one of the most widely used social class indicators in the US. It takes into account 
occupational prestige as well as income and education. $^{7}$

In developing countries, the baseline conceptual and methodological work by social stratification specialists to develop relevant scales and rankings of social class position is still in its early stages. In the absence of validated standard complex scales, we have selected education as possibly the best among objective measures to represent social class rankings in urban areas of developing countries. We make our selection based on three main criteria which are seen to be relevant to evaluations of social class measures from a health perspective. ${ }^{15}$ The first criterion relates to the practicality and feasibility of constructing the social class measure. The second criterion is the sensitivity of the measure to the social class life conditions known or suspected to influence health. These life conditions cover diverse elements of varying aetiological significance, among them the differential access to medical care resources, the differential exposure to a physically noxious environment, and the differential exposure to a sociopsychological environment that increases vulnerability to disease and ill-health. ${ }^{1}$ The third criterion is the ability of the measure to reflect the life conditions of the family as a co-residential unit of living. Health studies are becoming increasingly focused on the co-residential family. Even when individual health determinants are investigated, consideration is given to the fact that the individual lives within a family unit and is affected by the characteristics of that unit. 10
FEASIBILITY AND PRACTICALITY OF CONSTRUCTING THE MEASURE

Education has been shown to be moderately correlated with occupation and income so that no major variation in rankings compared to those two characteristics is expected. ${ }^{6}$ For our samples, the positive relation between education and occupation is demonstrated (table 1) for economically active individuals. However, education has definite advantages in terms of feasibility and practicality of translating a characteristic into a social class measure. For education, unlike occupation and income, is a characteristic which applies to every adult individual and is stable for most of his/her lifetime. In severely underdeveloped and rural areas of developing countries, and even in some low-income urban areas, education may be relatively poor and invariant with a large majority of illiterates. However, the point of focus in this paper is mainly populations in urban areas in transition where variation in educational opportunities for cohorts has occurred. Such areas form substantial segments of the total inhabited area in many developing countries. In such areas, education tends to vary from illiterate to university level, producing sizeable education groups.

Moreover, education is a characteristic that is easily obtainable and recordable in the detail necessary for social ranking. In contrast, both occupation and income suffer from difficulties of classification and recording in developing countries. First, the economies in developing countries tend to include

Table 1 Association between occupation and education for economically active population among adults in the Beirut (20+) and Amman (18+) samples

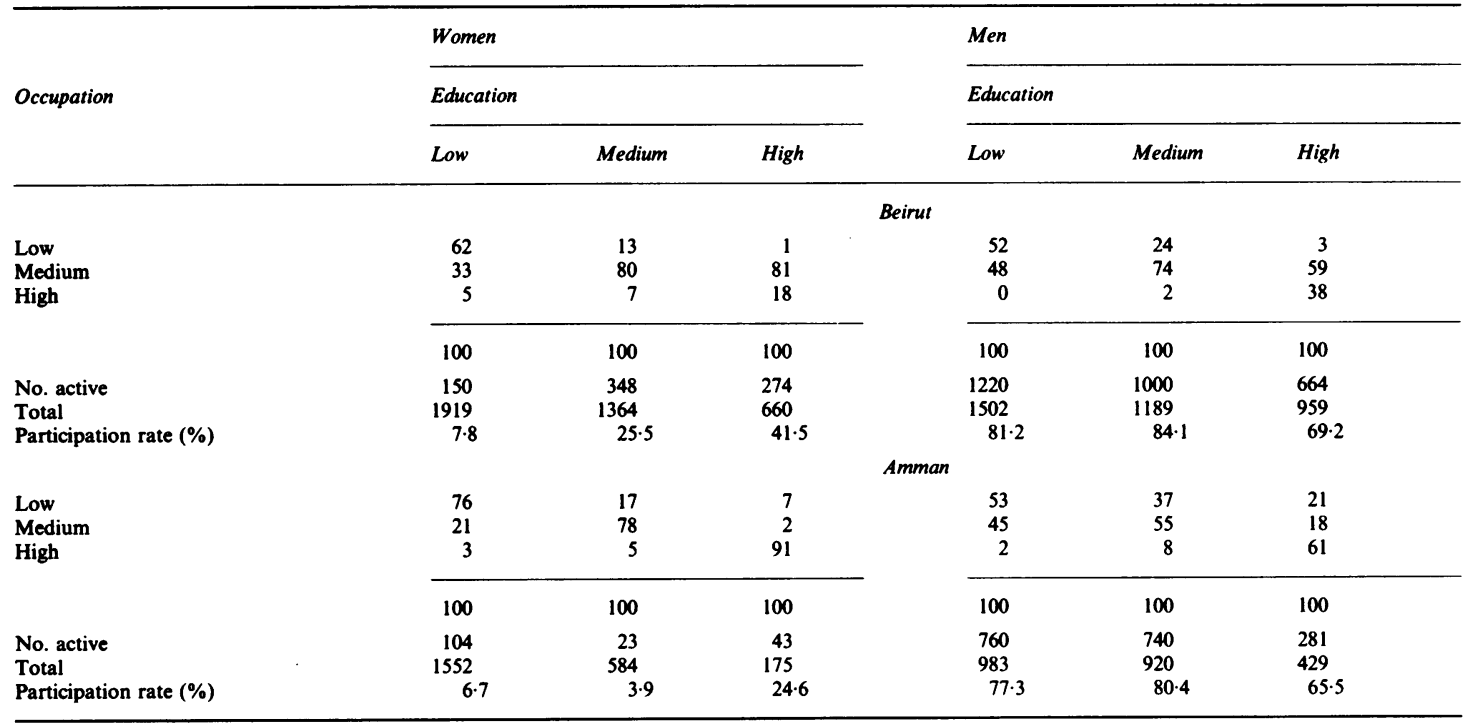


large, informal, and service sectors-compared to the dominance of the manufacturing sector in most industrialised developed countries-and this increases the difficulty of ranking occupations in line with economic and social standing. Secondly, classifying occupation into social class requires a detailed recording of occupations during data collection which is often difficult to achieve, particularly in the case of proxy informers such as spouses or other relatives. ${ }^{2}$ Thirdly, for the large majority of women with no formal employment (see table 1), no occupation can be recorded. ${ }^{11}$ Classifying a woman using the occupation of her husband or of the head of the family does not provide sufficient information about her which may be needed for analysis related to her health, as well as to family health conditions. A second group, other than women, for whom occupation presents a problem are retired persons. For such persons the significance of occupation-whether recorded as the main occupation during lifetime or as the last occupationin relation to health status seems to decline. ${ }^{5}$

In terms of income, well-known difficulties appear to be related to definitions of coverage of sources and to incomplete and inaccurate reporting not unique to, but perhaps more serious in, developing countries with their extensive, non-formal earning processes.

\section{SENSITIVITY OF THE MEASURE}

In terms of the second criterion, the main advantage of education as a basis for social class ranking is that it carries with it change not only in material conditions of living but also in levels of awareness and skills which enhances the sensitivity of the social class measure. ${ }^{1}$ Thus, in reflecting accessibility to medical care by social class, occupation and particularly income may represent affordability, but education adds the dimension of awareness of the need and sources of health care. Similarly, in reflecting conditions of the physical environment, occupation and particularly income may represent ability to obtain better housing conditions, but education carries the dimension of awareness of the importance of the physical environment and of protective and preventive behaviour in improving it and reducing its detrimental effects. Particularly in terms of the sociopsychological environment, education may be superior to the other two measures in that it reflects, on the one hand, stressful life events associated with social mobility, and it is related, on the other hand, to behaviour that requires awareness of the ill-effects of certain practices, such as smoking, overeating, and lack of exercise, on health. ${ }^{1}$

\section{FAMILY LEVEL REPRESENTATION}

Finally, in terms of the third evaluation criterion, we find that education is more amenable to producing a family-level measure of social class, particularly as compared to occupation. The usual practice in healthrelated studies is to use occupation or education of the head of the family as a measure of family level. However, some concern has been expressed as to the adequacy of representing the social class level of the family by relying only on the head's characteristics. 512 This practice is likely to produce a valid representation of social class in societies where homogeneity of characteristics is observed, particularly among adults. Such may be the case in developed country societies where husband and wife tend to be close in educational level and to be close to the educational level of their adult children. Yet, even in such societies, when a substantial proportion of married women work, it has been suggested that the occupation of both the husband and wife should be included when analysing various health conditions and experiences related to family health. ${ }^{5}$

For societies in transition, heterogeneity in educational levels of adults within the co-residential family is likely to be high, as males are the first to benefit from educational opportunities, and as children start attaining higher levels of education than their parents. These differentials are accentuated by prevalent living patterns where adult kin of two or three generations tend to live together (unpublished observations).

As an illustration of the heterogeneity between adult members of a family, men and women aged 20 years or older in the Beirut sample and 18 years or older in the Amman sample were classified in marital status groups according to discordance between their educational level and that of the head of the family in which they reside (table 2). Educational levels are summarised as low or high according to the distribution of the overall sample of families, as will be explained in the next section. It is seen that in both samples, the discordance is particularly high for single adults, both men and women, who mostly fall into a higher education class than the head of family. In the Beirut sample, but more so in the Amman sample, married women tend to be in a lower educational category than the head of family who is likely to be the husband.

In the context of Middle Eastern urban society, but equally applicable to societies in transition in other developing countries, Shorter ${ }^{13}$ has demonstrated the usefulness of delineating a family level of social class based on the educational levels of all adult individuals within the co-residential family. In the next section, we shall demonstrate the relative ease of constructing such a family educational score. Moreover, using data from the Beirut sample, we shall investigate the ability of such a family score to discriminate social class effects on family health compared to the more 
Table 2 Discordance between educational level category of adults compared to educational level category of head of family, in sex and marital status

\begin{tabular}{|c|c|c|c|c|c|c|}
\hline \multirow{2}{*}{$\begin{array}{l}\text { Educational level } \\
\text { adult } \mathrm{v} \text { head }\end{array}$} & \multicolumn{3}{|l|}{ Women } & \multicolumn{3}{|l|}{ Men } \\
\hline & Single & Married & Div/Sep/Wid & Single & Married & Div/Sep/Wid \\
\hline & \multicolumn{6}{|c|}{ Beirut } \\
\hline $\begin{array}{l}\% \text { Higher } \\
\% \text { Lower }\end{array}$ & $\begin{array}{l}55 \\
17\end{array}$ & $\begin{array}{l}15 \\
20\end{array}$ & $\begin{array}{l}14 \\
24\end{array}$ & $\begin{array}{r}58 \\
7\end{array}$ & $\begin{array}{l}5 \\
2\end{array}$ & $\begin{array}{l}16 \\
25\end{array}$ \\
\hline Total discordance & 72 & 35 & 38 & 65 & 7 & 80 \\
\hline $\begin{array}{l}\% \text { Higher } \\
\% \text { Lower }\end{array}$ & $\begin{array}{r}53 \\
5\end{array}$ & $\begin{array}{r}9 \\
17\end{array}$ & $\begin{array}{r}1 \\
18\end{array}$ & $\begin{array}{r}62 \\
2\end{array}$ & $\begin{array}{l}4 \\
2\end{array}$ & $\begin{array}{l}8 \\
8\end{array}$ \\
\hline Total discordance & 58 & 26 & 19 & 64 & 6 & 16 \\
\hline Number & 424 & 1551 & 349 & 757 & 1551 & 39 \\
\hline
\end{tabular}

standard representation based on the educational level of the head of family.

\section{A measure of social class based on average educational score in a family}

DEFINITION OF AVERAGE EDUCATIONAL SCORE IN A FAMILY

The mechanism suggested by Shorter ${ }^{13}$ for delineating social class by evaluating the educational levels of all adult individuals within the co-residential family requires that each adult be given a score based on his/her educational attainment and that an average score for the adults in the family be computed. For the two samples under study the scores were determined from the categories used in data collection as follows:

\section{Educational attainment}

Score

Illiterate

Did not complete primary

Completed primary

1

Did not complete secondary or technical

Completed secondary or technical

Did not complete university

Completed university or higher studies

In developing the average educational score for families, the question arose what should be considered the lower age limit for an adult. Shorter ${ }^{13}$ used 15 years of age as the lower limit. Yet the concern in this paper is to include in the social class measure only those adults who are likely to contribute to decision-making and family-functioning behaviour within the family. Such a contribution is believed to occur in the urban societies under consideration when an individual man or woman marries or becomes economically active, using a wide definition of economic activity for women to include household chores on a regular basis. ${ }^{11}$ In the two illustration areas, it was found that in the Amman sample a majority of men $(56 \%)$ and women $(55 \%)$ became 'active' at age 18, while in the Beirut sample the majority of men $(50 \%)$ and women $(58 \%)$ became 'active' at age 20 . Thus 18 and 20 years were chosen as the lower age limit for an adult to enter the computational process of the average educational score for the Amman and Beirut samples, respectively. Anyone who has married at an age below the lower limit (very few) was also included in the computation.

It must be noted that the averaging procedure used in determining the family level gives equal weight to all adult members, whereas their contribution to decision-making in the family may vary differentially according to the role in the family, to sex, and to age. Conceptualising the basis for, let alone estimating, differential weights is difficult, particularly in extended families. It would have to be culture-specific and based on close observations of family decisionmaking patterns.

The distribution of the two samples by average educational score is shown in table 3 . A dividing value as close to the median as possible, and yet meaningful in terms of the levels represented by the individual scores, was selected to categorise families into a lower and an upper social class. Thus the classification is relative to every sample and is meant to allow internal comparisons within samples and not between samples. For the Amman sample, families scoring less than 3

Table 3 Percent distribution of families by average educational score

\begin{tabular}{lcc}
\hline Average score & Beirut & Amman \\
\hline $1-1.99$ & 7.8 & 29.5 \\
$2-2.99$ & 17.3 & 37.9 \\
$3-3.99$ & 24.4 & 21.1 \\
$4-4.99$ & 21.9 & 10.9 \\
$5-5.99$ & 15.5 & 0.6 \\
$6-7.00$ & 13.0 & 0.1 \\
Number & 2752 & 1667 \\
\hline
\end{tabular}


(equivalent to less than completed primary on the individual score) were considered to be in the lower class stratum, otherwise in the upper stratum. For the Beirut sample, families scoring less than 4 (equivalent to completed primary or below on the individual score) were considered to be in the lower class stratum, otherwise in the upper stratum.

DISCORDANCE BETWEEN EDUCATION OF HEAD AND AVERAGE EDUCATIONAL SCORE IN A FAMILY

Summary comparisons, within family structure categories, of the average educational score with the education of the head are presented in table 4 . We note a substantial difference in both samples, particularly for the extended family form, in the average educational score compared to the educational level of the head. However, when grouping the two education measures into social class categories (using for the education of the head the same discriminatory value between lower and upper class as was used for the average educational score), we note (table 4) a reduction in the level of disagreement, a majority of families showing the same class for both determinations. Nevertheless, the average educational score is seen to give a different classification from the education of the head in a substantial proportion of families. The difference is particularly noteworthy for the extended and one-parent with never-married children family forms. The latter family form was revealed to consist mainly of a widowed older parent living with single adult children. For families consisting of a married couple with unmarried children in the Amman sample, the social class determination based on the education of the head compared to the average educational score is seen to change from high to low in $30 \%$ of cases, probably as a result of a lower level of education of the wife.

\section{DISCRIMINATORY POWER WITH HEALTH VARI A BLES}

The comparison of discriminatory power of the two education-based measures of social class is undertaken for the Beirut sample for which family health variables are available. It will be applied to those family forms that have shown substantial discordance in classification according to the two measures. The extended family category constitutes $18.3 \%$ of the sample, and the one-parent with never-married children category constitutes $10 \%$ of the sample. Thus altogether we are examining slightly less than onethird of the families in the Beirut sample.

The association of the two education-based measures with family health variables is tested by

Table 4 Education of head compared to average educational score within family structure categories

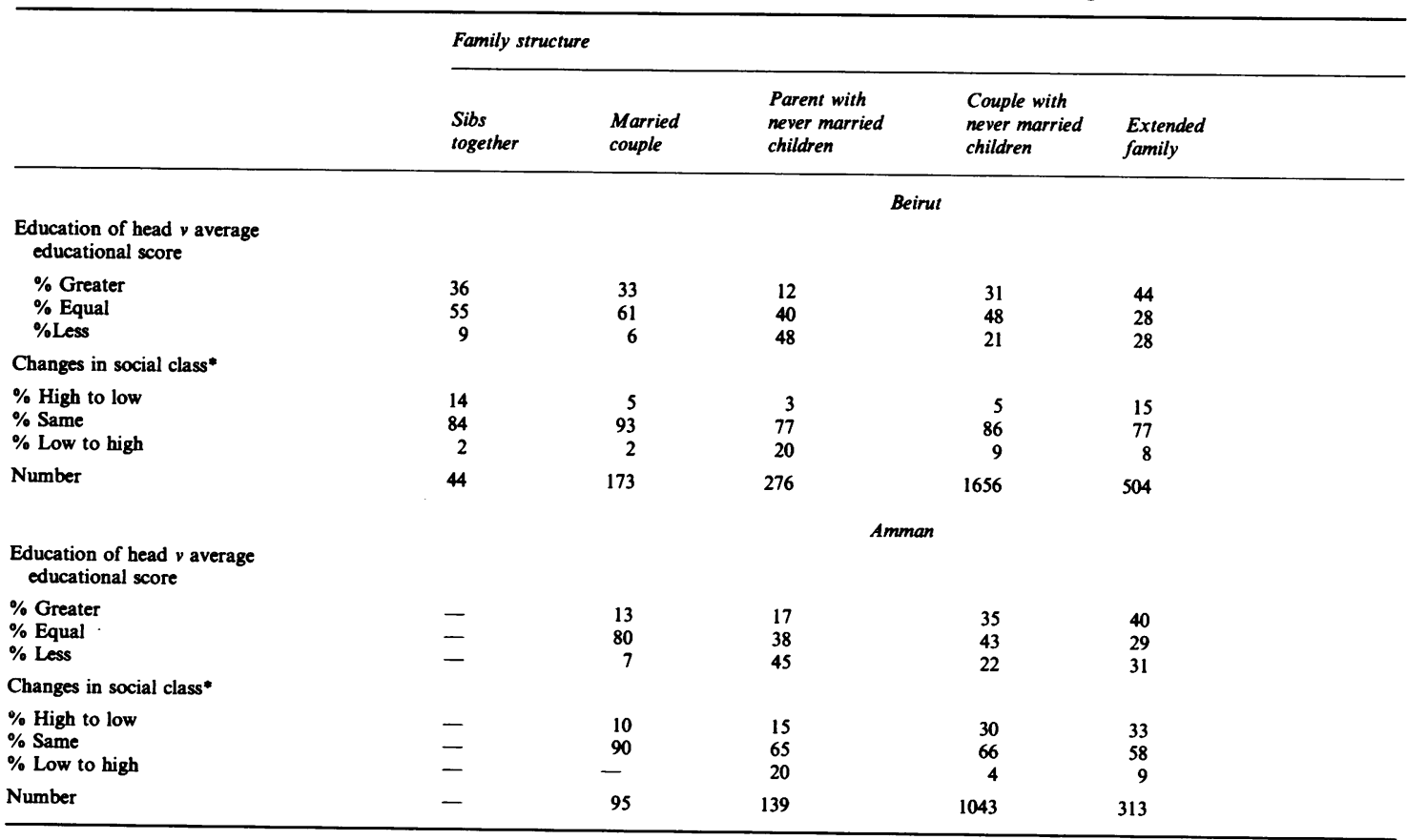

- Change from class based on education of head to class based on average educational score. 
using regression analysis in the form of multiple classification analysis ${ }^{14}(\mathrm{MCA})$. The main advantages of MCA are its ability to deal with categorical variables, and an easily interpretable output presentation. The family health variables include measures of morbidity, namely, (1) whether at least one member of the family has been hospitalised in the past year and (2) whether at least one member suffers from a chronic condition; measures of accessibility to medical care, namely, (3) whether the family has access to a family physician, and (4) whether the family has access to a family dentist; and measures of protective behaviour against environmental conditionsconsidered important particularly in the state of war and breakdown of services in Beirut during the past ten years, namely, (5) whether the family disinfects drinking water, and (6) whether the family uses soap or detergents with water in washing fruits and vegetables.

The models used include the following control variables: the demographic composition of the household covering (7) whether more than four persons reside permanently in the household, (8) whether at least one old person aged 65 years of age, and (9) whether at least one child under 15 years of age, reside permanently in the household; and (10) the religious affiliation being either Christian or Moslem. For every dependent variable two analyses are undertaken, one with the education of the head and one with the family educational score as a basis for social class determination. Each analysis is repeated for the extended and one-parent with never-married children family forms.
We can express the analytical model in the regression form underlying the MCA analysis as follows:

$Y_{i}=A+B_{1 j}+B_{2 k}+B_{3 m}+B_{4 n}+B_{5 r}$

where

$Y_{i} \quad$ is a binary dependent variable representing a family health variable as defined above.

A is the average rate in the underlying population related to the family health variable under consideration.

$B_{1 j} \quad$ is the adjustment to the average rate induced by category $j$ of the family size variable $(j=1,2)$.

$B_{2 k}$ is the adjustment to the average rate induced by category $m$ of the children in the household variable $(m=1,2)$.

$B_{3 m}$ is the adjustment to the average rate induced by category $\mathrm{m}$ of the children in the household variable $(m=1,2)$.

$B_{4 n}$ is the adjustment to the average rate induced by category $n$ of the religion variable $(n=1,2)$.

$B_{5 r}$ is the adjustment to the average rate induced by category $r$ of the social class measure $(r=1,2)$.

The results of the analysis are shown in table 5. They generally show negative trends of morbidity, and positive trends of accessibility to medical care and of protective behaviour against the environment, with both measures of social class. The trend is found to be significant for the accessibility and environmental variables in both extended (with the exception of water disinfection) and one-parent family forms, but not for the morbidity variables.

Table 5 Multiple classification analysis results comparing discriminatory power of social class measures in terms of family health variables for the Beirut sample

\begin{tabular}{|c|c|c|c|c|c|c|c|c|c|}
\hline \multirow{3}{*}{$\begin{array}{l}\text { Family health } \\
\text { variable }\end{array}$} & \multirow{3}{*}{$\begin{array}{l}\text { Grand } \\
\text { mean }\end{array}$} & \multicolumn{8}{|c|}{ Adjustment to grand mean } \\
\hline & & \multicolumn{4}{|c|}{ Education of head } & \multicolumn{4}{|c|}{ Average educational score } \\
\hline & & Low & High & $P$ & $R^{2}$ & Low & High & $P$ & $R^{2}$ \\
\hline \multicolumn{10}{|l|}{ Extended households } \\
\hline $\begin{array}{l}\text { Hospitalisation } \\
\text { Chronic condition } \\
\text { Family physician } \\
\text { Family dentist } \\
\text { Water disinfection } \\
\text { Wash fruits \& vegetables }\end{array}$ & $\begin{array}{l}0.41 \\
0.83 \\
0.52 \\
0.55 \\
0.17 \\
0.44\end{array}$ & $\begin{array}{r}0.00 \\
0.01 \\
-0.05 \\
-0.10 \\
-0.05 \\
-0.06\end{array}$ & $\begin{array}{r}0.00 \\
-0.01 \\
0.08 \\
0.13 \\
0.06 \\
0.07\end{array}$ & $\begin{array}{l}0.93 \\
0.71 \\
0.00 \\
0.00 \\
0.00 \\
0.00\end{array}$ & $\begin{array}{l}0.020 \\
0.010 \\
0.068 \\
0.081 \\
0.037 \\
0.190\end{array}$ & $\begin{array}{r}0.03 \\
0.01 \\
-0.06 \\
-0.09 \\
-0.01 \\
-0.07\end{array}$ & $\begin{array}{r}0.05 \\
-0.02 \\
0.08 \\
0.13 \\
0.01 \\
0 \cdot 10\end{array}$ & $\begin{array}{l}0.07 \\
0.30 \\
0.00 \\
0.00 \\
0.56 \\
0.00\end{array}$ & $\begin{array}{l}0.027 \\
0.012 \\
0.065 \\
0.073 \\
0.019 \\
0.200\end{array}$ \\
\hline Number & 481 & 267 & 214 & & & 288 & 193 & & \\
\hline \multicolumn{10}{|l|}{ One-parent households } \\
\hline $\begin{array}{l}\text { Hospitalisation } \\
\text { Chronic condition } \\
\text { Family physician } \\
\text { Family dentist } \\
\text { Water disinfection } \\
\text { Wash fruits \& vegetables }\end{array}$ & $\begin{array}{l}0.26 \\
0.68 \\
0.46 \\
0.57 \\
0 \cdot 18 \\
0.51\end{array}$ & $\begin{array}{r}0.01 \\
0.01 \\
-0.09 \\
-0.06 \\
0.05 \\
-0.05\end{array}$ & $\begin{array}{r}0.02 \\
-0.02 \\
0.15 \\
0.11 \\
0.08 \\
0.09\end{array}$ & $\begin{array}{l}0.51 \\
0.59 \\
0.00 \\
0.01 \\
0.01 \\
0.03\end{array}$ & $\begin{array}{l}0.009 \\
0.009 \\
0.073 \\
0.048 \\
0.041 \\
0.092\end{array}$ & $\begin{array}{r}0.03 \\
0.04 \\
-0.11 \\
-0.14 \\
-0.06 \\
-0.11\end{array}$ & $\begin{array}{r}0.03 \\
-0.03 \\
0.09 \\
0.12 \\
0.05 \\
0.09\end{array}$ & $\begin{array}{l}0.30 \\
0.24 \\
0.00 \\
0.00 \\
0.04 \\
0.00\end{array}$ & $\begin{array}{l}0.012 \\
0.013 \\
0.061 \\
0.079 \\
0.034 \\
0.107\end{array}$ \\
\hline Number & 264 & 168 & 96 & & & 118 & 146 & & \\
\hline
\end{tabular}


In comparing the association of the two social class measures with the family health variables, we make the following observations. First, the models using the average educational score explain a larger percentage of the variation in 7 of the 12 analyses undertaken. However, the differences in percentage explained are mostly small. Secondly, the average educational score demonstrates significance for seven of the analyses; yet the education of the head shows significance for one more, totalling eight significant coefficients. Nevertheless, for four of the seven analyses in which both measures show significance, the average educational score reveals better discrimination in terms of the distance between the adjustments to the average rate of the family health variable induced by the categories of the measure (for accessibility to physician and for washing fruits and vegetables in extended households, and for accessibility to dentist and for washing fruits and vegetables in one-parent households). Moreover, despite the lack of significance of both social class measures for the morbidity variables, we note that the average educational score performs better than the education of head according to the criteria of P-value and to distance achieved between adjustments, especially for the hospitalisation variable in extended households.

\section{Conclusion}

In conclusion, it is emphasised that the relative merits of the various measures of social class are not fixed but change over time and space, depending on variations that occur in the social and economic structure. ${ }^{5}$ For urban areas in transition in developing countries, we have argued that a measure of social class based on education seems to be a more sensitive and feasible measure compared to occupation or income, in the absence of standard complex scales based on sound methodological research. Moreover, we have suggested that a social class measure based on average educational score of adults in the family may be a more valid representation of a family-level social position than a social class measure based on the educational level of the head. This conclusion is reached for urban populations in two developing country societies where heterogeneity of educational levels exists within the family. In discriminating associations with family health variables, the performance of the average educational score was often better than, but not consistently superior to, education of the head.
We express our gratitude to the Urban Development Department of Jordan for kindly making available to us the data from the Amman areas. We thank Dr Frederic Shorter, senior representative of the Population Council in the Middle East and North Africa, and Dr Haroutune Armenian, Dean of the Faculty of Health Sciences at the American University of Beirut, for valuable comments on the manuscript. Maha Abul Naja is also thanked for typing the manuscript.

\section{References}

${ }^{1}$ Syme SL, Berkman LF. Social class, susceptibility and sickness. Am J Epidemiol 1976; 104: 1-8.

${ }^{2}$ Abramson JH, Gofin R, Habib J, Pridan H, Gofin J. Indicators of social class: a comparative appraisal of measures for use in epidemiological studies. Soc Sci Med 1982; 16: 1739-46.

${ }^{3}$ Bisharat L, Mosley WH, Shorter FC. A Baseline health and population assessment for the upgrading areas of Amman. Amman: Urban Development Department, 1980.

${ }^{4}$ Zurayk H, Awn S, Ashkar A, Asad M, Rahhal S, Azar A. Introduction and methodology. In Zurayk $\mathrm{H}$, Armenian $\mathrm{H}$, eds. Beirut 1984: a population and health profile. Beirut: American University of Beirut, 1985; 9.

${ }^{5}$ Morgan M. Measuring social inequality: occupational classifications and their alternatives. Community Med 1983; 5: 116-24.

${ }^{6}$ Otto LB. Class and status in family research. $J$ Mar Fam 1975; 37: 315-32.

${ }^{7}$ Miller DC. Handbook of research design and social measurement. New York and London: Longman, 1983.

${ }^{8}$ Morgan M, Chinn S. ACORN group, social class, and child health. J Epidemiol Community Health 1983; 37: 196-203.

${ }^{9}$ Pole DJ, Ikeme AC. Socioeconomic scoring in an urban area of a developing country. Bull WHO 1979; 53: 476-9.

${ }^{10}$ World Health Organization. Health and the family: studies on the demography of family life cycles and their healthy implications. Geneva: WHO, 1978.

${ }^{11}$ Zurayk H. Women's economic participation. In Shorter FC, Zurayk H, eds. Population factors in development planning in the Middle East. New York: The Population Council, 1985; 3.

12 Rahman M, Rahman MM, Wojtyniak B, Aziz KMS. Impact of environmental sanitation and crowding on infant mortality in rural Bangladesh. Lancet 1985; 2 (8445): 28-31.

${ }^{13}$ Shorter FC. Demographic measures of inequality and development. In Shorter FC, Zurayk H. Population factors in development planning in the Middle East. New York: The Population Council 1985.

${ }^{14}$ Andrews FM, Morgan JN, Sonquist JA, Klem L. Multiple classification analysis. A report on a computer program for multiple regression using categorical predictors. Ann Arbor: The University of Michigan, 1973. 